Transnational Business Governance Interactions Project Working Paper No. 30

June 2018

\title{
Transnational Business Governance Interactions and Financial Regulation Change: A Case of Asian Financial Markets
}

\section{Simin Gao}

Tsinghua University

\section{Christopher Chen}

Singapore Management University

This paper is available free of charge from www.tgiforum.org

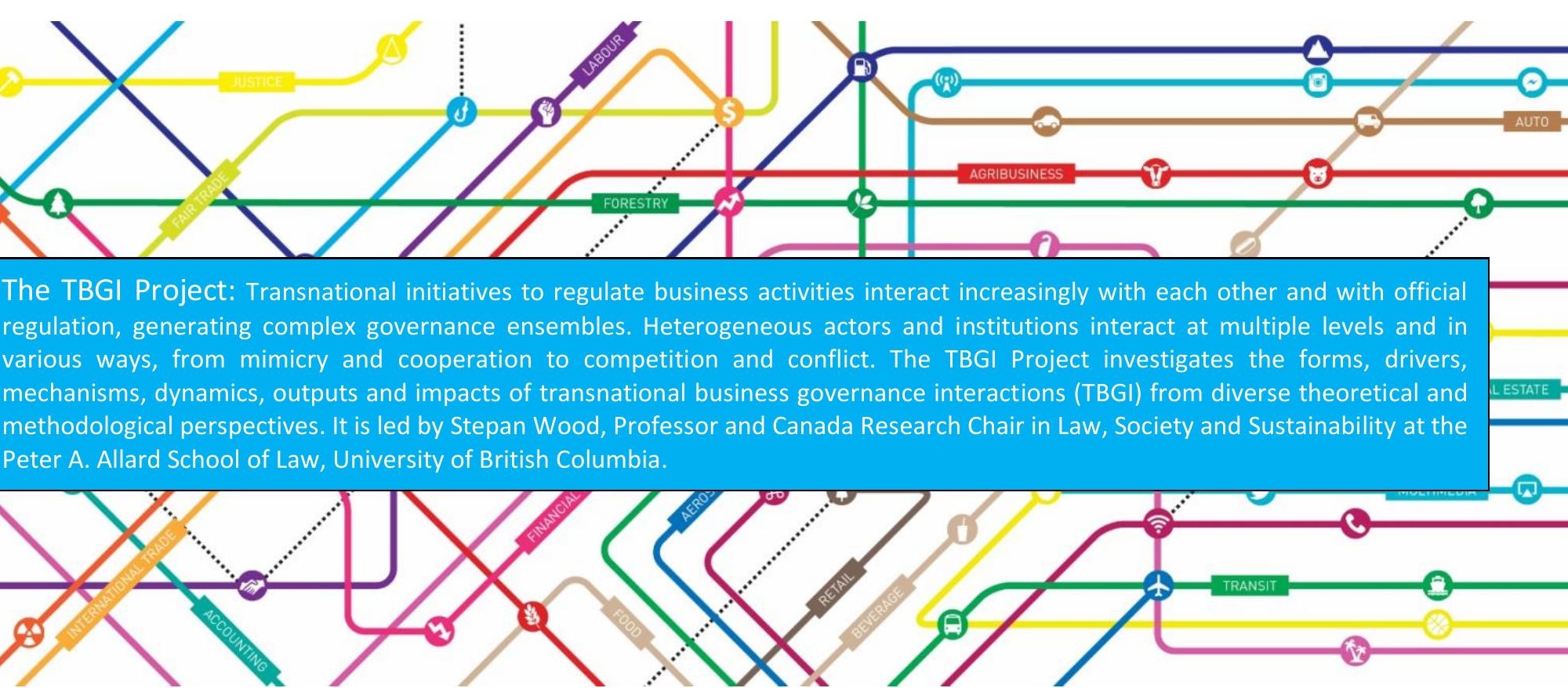




\title{
Transnational Business Governance Interactions and Financial Regulation Change: A Case of Asian Financial Markets
}

\author{
Simin Gao and Christopher Chen $^{1}$
}

\begin{abstract}
This chapter examines the interactions of transnational business governance schemes regulating the global derivatives markets with multiple levels of interactions. The chapter describes the process of interactions via the theory of isomorphism. First, after examining the interactions of futures exchanges, we identify that governance techniques among futures exchanges are rather similar, illustrating the forces of mimetic and normative isomorphism. Second, the monopoly of the International Swaps and Derivatives Association (ISDA) scheme in the over-the-counter (OTC) market provides signs of mimetic isomorphism. Third, through imparity of market power and major market dealers, the ISDA scheme became the only governance scheme for the over-the-counter (OTC) market. This shows some signs of coercive isomorphism, though there may also exist a certain degree of divergence of development for certain rules.
\end{abstract}

\section{Keywords}

Derivatives, financial regulations, ISDA, isomorphism, convergence

\section{Introduction}

This chapter argues that transnational business governance interactions (TBGI) play an important role in the two main competing schemes governing global derivative markets. On the one hand, the overthe-counter (OTC) market has developed a single monopolistic transnational business governance (TBG) scheme in the form of standard documentation published by the International Swaps and Derivatives Association (ISDA), which governs over 90\% all of derivatives trading (Henderson 2010a, 803). On the other hand, for the market for exchange-traded products (for simplicity, 'futures' ${ }^{1}$ ) has seen multiple exchanges created around the world since the 19th century, offering multiple poles in the global governance of futures trading. While each futures exchange has a similar business and governance model, there is no monopoly like the ISDA in the market for exchange-traded derivatives.

${ }^{1}$ Simin Gao, Associate Professor of Law, Tsinghua University, School of Law. sgao@mail.tsinghua.edu.cn. Christopher Chen, Associate Professor of Law, Singapore Management University. chchen@smu.edu.sg.

A revised version of this paper is forthcoming in Stepan Wood et al., eds. Transnational Business Governance Interactions: Empowering Marginalized Actors and Enhancing Regulatory Quality.

Cheltenham, UK: Edward Elgar. 
The governance schemes of the global derivatives market have several levels of interactions. On the one hand, the ISDA scheme and the futures schemes interact with one another. For example, some OTC trades are cleared in a clearing house that underlies the futures scheme. On the other hand, the global derivatives governance system interacts with state and supranational regulators, especially as the global financial system was reformed and regulation of derivatives trading-in particular of OTC derivatives-was tightened in the wake of the global financial crisis.

This chapter considers these interactions and adds another angle: the interaction between East and West. We use these terms as shorthand for East and Southeast Asia, on one hand, and Europe, the UK, North America and Australia on the other. The futures schemes and ISDA scheme both originated in and reflect the social and economic conditions of the advanced Western capitalist world. The futures schemes in both West and East have largely the same governance model. In addition, the ISDA standard documentation has become a global script. Even countries that do not share the common law tradition of London or New York adopted the essence of these contractual norms from 1980s onward. Since the financial crisis of 2008, Asian markets have adopted to various degrees regulatory reform proposals aimed at Western derivatives markets and market participants. Tis chapter asks why similar governance regimes are adopted across the globe for derivatives trading, whether futures exchanges or the OTC market. In particular, we examine the implementation of the ISDA and futures schemes in Asia and the associated interaction between the West and Far East in a market dominated by American, British and European banks.

In other words, our key question is why there seems to be a high degree of convergence of norms governing derivatives markets. This chapter will focus on the techniques and strategies adopted by some East Asian countries in light of TBG schemes originating in the West. The chapter considers what drives East Asian markets to implement the same futures and ISDA schemes to govern their derivatives market (Eberlein et al. 2014, 9-10). We examine the isomorphic forces behind the global convergence (and to a lesser degree divergence) of governance regimes of futures exchanges and the OTC market from the angle of markets in the Far East. The chapter applies the theory of isomorphism to illustrate different forces that drive regulators and market operators in the East to adopt governance schemes created in the West and to examine factors that may cause some degrees of divergence.

Part I introduces the drivers of isomorphism and explores the general character of interactions among TBG regimes. Part II examines the parallel schemes governing the global futures and OTC derivatives markets. In addition to describing the derivatives market generally, we identify isomorphic forces that drove the convergence of governance norms. Part III concludes the chapter.

\section{Convergence or Divergence of Global Business Governance Norms}

\section{A. Drivers of Isomorphism}

Isomorphism is a concept in organizational theory that captures the "process of homogenization" that forces "one unit in a population to resemble other units that face the same set of environmental conditions" (DiMaggio and Powell 1983, 149). In an environment with multiple organizations, some organizations' responses to the environment may lead others to respond similarly (Schelling 1978). Isomorphism is a process by which an organization comes to resemble others due to the same environmental conditions (Hawley 1968). There are three kinds of isomorphism: coercive isomorphism "stems from political influence and the problem of legitimacy"; mimetic isomorphism results from "standard responses to uncertainty"; and normative isomorphism "associates with professionalization" (DiMaggio and Powell 1983, 150). Coercive isomorphism is driven by the pressures of powerful actors. Transnational institutional convergence is possible "if existing institutions have been thoroughly discredited, morally or functionally, and, at the same time, if there is a powerful external actor who is able 
to enforce a new institutional design" (Beckert 2010, 153). In other words, the advanced institutional design of the powerful states can be adopted by the marginal states when existing institutions in the latter need changing.

Professionals play an important role in isomorphism. For instance, "competing states are subject to normative isomorphic pressure through the professional networks of state managers. These states are also pressured to imitate or mimic policies of other states to keep up in the competition for private investment and economic development" (Leicht and Jenkins 1998, 1327). The media for mimetic isomorphism may be "in-service educational programs, consultant arrangements, employer professional school networks, and trade journals" (DiMaggio \& Powell, 1991, 74). Normative isomorphism can also be used to interpret the roles of professionals and trade associations in driving the convergence of rulemaking in the derivative markets by different states. An example is the operation of the ISDA, the professional association of derivative traders, which we discuss below in Part II. The initial goal of the ISDA is to create standard documentation to facilitate trading. For the professionals in derivatives markets, using standard documents for trading can minimise the risk of legal uncertainty. That is why we observe that ISDA, as representative of trading professionals, plays a very active role in lobbying lawmakers in different jurisdictions to recognize the legitimacy of the key mechanisms built by ISDA standard contracts, and to the adopt ISDA standard forms globally, including in Asian markets.

Gaining legitimacy with external constituents is a force behind isomorphism when those constituents expect an organization to function. The driving force behind mimetic isomorphism is "the legitimation that an institutional regulation finds within an organizational field" (Beckert 2010, 158) against the uncertainty of solutions (Cyert \& March, 1963). Convergence in rulemaking becomes possible because the institution in some countries becomes a successful model for other countries to follow to reduce the uncertainty of creating their own rules (Trampusch 2000; Beckert 2010, 158). Innovation by one organization to decrease uncertainty may be copied by other organizations (Alchian, 1950). Therefore, the direction of convergence of financial rules is usually from the successful and powerful markets to the marginal ones. The governance model of the Asian derivatives exchanges demonstrates this phenomenon of mimetic isomorphism. For market operators in emerging markets, the simplest way to create a futures exchange is to follow a well-established model from developed countries, which has proved to be successful and efficient. With large Western exchanges and central counterparties (CCPs, or clearing houses) seeming to run well, mimicking the Western model is perhaps the safest approach. This may explain why futures exchanges in Asia all adopted the same governance model.

As we will elaborate further in Part III, different isomorphic forces operate in the global derivatives market. For example, we have seen mimetic and normative isomorphism in the way modern futures exchanges are modelled around the world. In the early stage of development of the OTC market, we also saw the force of mimetic isomorphism as global market dealers helped to spread the ISDA standard forms to Asian markets. In the post-financial crisis era, we gradually saw more coercive isomorphism as market reforms were proposed by the US and EU before gradually being implemented in major Asian markets. In 2009, the $\mathrm{G} 20$ declared a commitment to strengthening the international financial regulatory system, with three major reform proposals for derivatives trading: the trading mandate to force OTC trades to move to exchanges, the clearing mandate to require centralized clearing of OTC trades, and the reporting mandate to prescribe trading parties to report information about a trade to a trade repository. To gain legitimacy in the global clearing market and compete for a bigger share, some Asian markets started to clear OTC trades even before the implementation of the clearing mandate. However, some divergence of rules persisted where Asian national interests were not aligned with those of major markets like the US or EU. Asian countries have been relatively slow to implement the trading and clearing mandates, though the reporting mandate has been largely implemented at least in Hong Kong and Singapore (Gao and Chen 2017). 


\section{B. The Substance and Character of Interactions}

\section{The Substance of Interaction}

We can further consider in general terms the norms in financial law underlying the global derivatives market and how they might interact with each other on the global level. The substance of global business regulation is a hybrid of domestic and international law (Koh 2006), which can include both state and non-state norms and can be applied across more than one country or jurisdiction (Friedman 1996). Non-state norms, including nonbinding standards, the lex mercatoria, model laws, and common approaches or standards for institutional monitoring, are elements of the international business order.

This hybrid normativity is particularly interesting in the arena of financial law, which involves not only territory-based regulations but also international and non-state regulatory norms. For example, the governance schemes of the global derivatives market include not only national law in each market but also transnational regulatory norms.

The ISDA master agreement operates as a non-state norm regulating the bilateral relationship of trading parties for the vast majority of OTC derivatives transactions. In addition to the ISDA standard documentation, the regulatory regime for the OTC market consists of state regulations, private practices, regulatory standards set by international organizations and the "best practices" of other jurisdictions. On the international level, the three mandates for OTC derivatives market regulation (i.e. the trading, clearing and reporting mandates) were prescribed by the $\mathrm{G} 20$ in 2009 and are monitored by the Financial Stability Board. The mandates must be implemented by national laws (e.g. the Dodd-Frank Act ${ }^{2}$ in the US, along with subsidiary rules issued by the Commodity Futures Trading Commission).

In contrast, regulation of futures exchanges is rooted in national law, though the governance model is similar around the world. In addition, especially after the global crisis, some global norms have been created to improve the regulatory standards and legal infrastructure of the OTC market, such as the G20's reporting, clearing and trading mandates. The hybrid substance of transnational financial law illustrates the "multiple centrifugal tendencies" (Teubner 2004, 3) of global society, which is an essential condition for transnational interaction.

\section{The Directions of Interaction}

Market forces play an important role in driving the transnational interaction of business governance norms. The direction of flow of business governance norms is determined by asymmetric market power, namely from the center market to the marginal markets. Countries with sophisticated markets can make the rules and export them to other countries through ongoing business communications. Such legal norms may also originate from a leading country's legislature, and such state authorization may have great influence for encouraging other countries to adopt or transplant foreign rules. For example, the U.S. Sarbanes-Oxley Act of $2002^{3}$ became a model for a number of other states (Weber 2010).

In the arena of derivatives, the US and UK are the dominant markets (Bank of International Settlement 2013). Laws made in these core markets are widely regarded as the models for smaller players to follow. Business lawmaking in the most powerful countries has both domestic and international consequences due to these transnational interactions. Considering the potential effect of their rules in international society, the most powerful markets are generally more conscious and deliberate in their rule-making (Coffee 2014).

Marginal markets are not simply passive receivers, however. They may actively adopt the best practices and international standards that are beneficial for their countries. As Walter shows, domestic politics in Asian countries play an important role in the adoption of financial standards set by international 
organizations such as the G-7 (Walter 2008, 173). For example, the Asian market (even in countries following the civil law tradition) embraces the ISDA master agreement as the governing contractual norm since it facilitates trading with global market dealers, even though it is largely structured on New York and English law. The degree of acceptance of the G20's three mandates also varies, reflecting more national concerns. We have seen a higher degree of adoption and convergence of rules around the reporting mandate, which requires traders to report derivatives trades to a repository in order to improve transparency. Nonetheless, major Asian markets such as Hong Kong and Singapore have lagged behind in implementation of the mandatory clearing requirement for OTC derivatives due to some national interests and concerns about the solvency of clearing houses (Gao and Chen 2017). Thus, marginal markets might not adopt central governance norms wholesale if countervailing national interests affect their strategies in adopting certain norms.

\section{What Determines the Effects of Interactions?}

The effects of transnational business governance interactions can differ. Some interactions may directly influence the local legislature and may even promote isomorphism of business rules in different jurisdictions. Some interaction may have no significant effects. What determines these effects?

One important factor is the norms that are the subject of interaction. Shaffer (2012) finds that legal norms that interact with one another usually have certain common characteristics (such as legitimacy, clarity and coherence) that can produce domestic legal and institutional changes. In addition, a receiving state's relation to the transnational legal order and its own domestic context are also critical factors in determining the effects of downloading legal norms (Shaffer 2012). These effects depend partly on the norms' degree of fit with the receiving country's law and political economy. As Kanda and Milhaupt point out, there are two kinds of fit: "[M]icro-fit is how well the imported rule complements the preexisting legal infrastructure in the host country. Macro-fit is how well the imported rule complements the pre-existing institutions of the political economy in the host country" (Kanda and Milhaupt 2003). For example, as the ISDA form is constructed upon English and New York law, its fit is higher in Singapore and Hong Kong than in other Asian markets because of their common law heritage and the presence of many international banks in both markets.

With this background in mind, we turn now to the TBG schemes governing global derivatives, and their interactions. In addition to a general discussion on the interactions between different schemes and how the interactions evolve, we also focus on how the schemes flow from core markets in the West to some Asian markets.

\section{East-West Interactions in Transnational Business Governance Schemes for Global Derivatives Markets}

\section{A. Characteristics of Derivatives Markets}

The futures and OTC markets are both global and each represents a kind of transnational business governance scheme. The futures market has a far longer history. Since the establishment of the Chicago Board of Trade in the mid-19th century, the futures market blossomed as a trading forum for many agricultural products before expanding into financial futures (e.g. interest rate or index futures) and energy products (e.g. crude oil futures) since the 1970s. In contrast, the rise of OTC derivatives is fairly recent. The market kicked off since the 1980s at an exponential speed.

The development of governance regimes of the two market sectors followed different paths. American and European giants dominated the futures market. According to the Bank of International Settlement, the total open interests in all futures exchange in North America amounted to US\$15.705 
trillion at the end of 2015, with the amount in Europe being US\$ 7.08 trillion and US\$ 1.775 trillion in Asia and Pacific (Bank of International Settlement 2016). However, many Asian markets still create their own futures exchanges. For example, the Shanghai Futures Exchange was created in 1999 offering a range of metal-linked contracts.

Trading volume in the OTC market is much larger than that of all futures exchanges combined. Pursuant to statistics provided in the website of the Bank of International Settlement, the total notional amount outstanding as in the first half of 2017 is US\$ 542.435 trillion, ${ }^{4}$ in contrast with the total open interests worth US\$33.694 billion in June 2017 for exchange-traded futures and options. ${ }^{5}$

Like the futures market, the OTC market also has two clear power centers. According to the Bank of International Settlement, the daily average of OTC interest rate derivatives in the UK amounted to US\$ 1,347.74 trillion, followed by the US (US\$ 628.15 trillion), France (US\$202.21 trillion), and Germany (US\$ 101.34 trillion). In Asia, the biggest market is Japan (US\$ 67.14 trillion, $5^{\text {th }}$ in the world) with Singapore (US\$ 37.14 trillion) in $8^{\text {th }}$ position and Hong Kong (US\$27.90 trillion) in $12^{\text {th }}$. Thus, both the futures and OTC derivatives markets are dominated by traders in the Western world. This has a profound effect on how the norms and governance schemes are designed and implemented on the global level.

\section{B. Mimetic and Normative Isomorphic Forces Shaping the Futures Schemes}

Forces of mimetic and normative isomorphism influence the way Asian markets adopt governance schemes regulating the exchange-traded futures market. The fact that an exchange has to be situated physically in a particular country (even in the age of electronic trading) generates multiple TBG schemes regarding the futures, with each futures exchange being a TBG scheme. This multiplicity leads to multilateral interactions of governance schemes. However, the governance structure of a futures exchange is built largely on the same pattern around the world, though details vary.

The hallmark of futures trading is that all exchange-traded contracts (whether futures contracts or options) are standardized to the point that price is the only issue that requires negotiation. This feature allows market participants to buy and sell multiple contracts at the same time. A typical futures market is run by an exchange operator (e.g. Chicago Mercantile Exchange (CME)), which sets out trading rules and specifies the types of contracts that are available for trading. To trade directly in an exchange, a market participant must become an exchange member, which are usually large banks, financial institutions or fund management firms. Other traders have to have a contract with those members or a clearing house to enjoy trading and clearing services. In large exchanges, there can be multiple layers of members with different rights and obligations.

Typically, the making of a contract between two traders sets off a chain of novation of contracts until a central counterparty (CCP, or clearing house) becomes the ultimate counterparty to all contracts. The standardization of contracts then allows the CCP to calculate any profit or loss incurred by a trader. To secure payment obligations from trading positions incurred by a market participant, the market has developed the margin system, under which a trader has to pay a certain sum of money (or liquid asset) to a CCP or clearing member as collateral. The value of the margin account would be marked to the market on a daily basis to reflect profits or losses incurred by the trader, who must post more collateral if the value of the margin account drops below a certain level (i.e. the margin call). Otherwise, his trading positions could be closed out to stop losses. This is an essential feature of the futures market to ensure the solvency and soundness of the futures market and the clearing system. It operates through a pyramid structure of governance from national regulatory rules at the apex, down through exchange and clearing rules to contractual terms and membership agreements.

The same model (i.e. exchange trading with trades cleared by a CCP) has been applied in virtually all major futures exchange in the world, though details may differ (e.g. the exact margin rate or acceptable instruments for margin). This raises an interesting question: why does a generic model of governance 
scheme govern domestic and international trading activities? We argue that there could be two isomorphic forces behind the phenomenon.

On the one hand, there could be mimetic isomorphism. For market operators in emerging markets, the simplest way to create a futures exchange is to follow a well-established model in developed countries, which is relatively transparent and rarely fails with only three incidents of CCP insolvency in the past 50 years (Wendt 2015, 11, note 7). With large Western exchanges and CCPs seemingly running very well, mimicking the Western model is perhaps the safest approach. This may explain why most (if not all) futures exchange in Asia seems adopt the same governance model. For example, in both the Singapore Exchange and Hong Kong Exchange, direct participation of trading and clearing is controlled by membership ${ }^{6}$ with different margin requirements for different products, the same model adopted in leading futures exchanges in the West. ${ }^{7}$

On the other hand, we also observe signs of normative isomorphism. The network of international banks and professionals might also help to spread the use of the same governance model to emerging markets, as they are more familiar with the trading and clearing process if difference futures markets in different countries are largely running on the same governance platform. Large financial institutions, as market-makers, should prefer a new exchange in an emerging market to operate in the same governance model so that they might reduce compliance and transaction costs. It might also benefit the local market operator if the governance scheme is similar to those in the West so as to attract Western traders to trade in the local market. In addition, advisers who help to set up a new futures exchange are most likely those professionals or bankers who are familiar with the Western model. Those factors might explain why the governance schemes of the futures around the world seem to converge.

However, globalisation and the interconnection of the financial markets could offer some challenges to the governance of futures schemes, given that futures schemes are still largely regulated by the national law of the jurisdiction where an exchange or CCP is situated. The worst-case scenario is when a CCP goes bankrupt. It may be less of a problem when two or more CCPs are in the same jurisdiction governed by the same laws. However, when they are situated in different jurisdictions (especially in places with different legal systems), there could be some legal complications. It is not helpful that a country may be more inclined to ring-fence local assets in the case of bankruptcy, making it more challenging to maintain cross-margin in a case where a large participant or a CCP becomes insolvent. This may explain why cross-exchange trading amongst different countries has not reached a larger scale. It is hard to predict how legal issues may be resolved. To resolve such issues, harmonization of laws regarding security interests and enforceability of collateral as well as insolvency rules may be the ultimate solution. If so, it would lead to less polycentrism in the underlying regulatory structure of futures schemes in the world.

Consolidation of exchange and clearing businesses provides an additional angle of interactions between governance schemes. For example, the US has seen the creation of the CME group, the merger of the two Chicago giants - the Chicago Mercantile Exchange and Chicago Board of Trade-in 2007. The Eurex, a large futures exchanges based in Europe, created a trading platform in Singapore in 2009, while the Intercontinental Exchange acquired New York Stock Exchange (NYSE) in 2012. These mergers may create a new range of regulatory issues (Kokkoris and Olivares-Caminal 2007, 2008; Schammo 2008).

In contrast, in most Asian markets, it is still very common to have a national monopoly or duopoly of futures exchanges. In terms of ownership, some exchanges in Asia are still more or less owned and controlled by the state (e.g., in Taiwan or China), while some exchanges are publicly traded companies (e.g., SGX in Singapore and HKEx in Hong Kong). This creates a different environment of interactions among futures exchanges or CCPs in Asia compared to those in the US or Europe. If we consider that an exchange and CCP are fundamental financial infrastructure in a country, it is natural that national interest is often an important concern especially when foreign ownership is involved.

A higher level issue concerns the regulation of exchanges and CCPs. In many markets in Asia, a futures exchange and CCP are bundled together. This is the traditional "vertical silo" approach, in which 
contracts traded on an exchange must be assigned to a specific CCP for clearing. This is still the case in most futures exchanges in Asia. Adopting the silo approach, a CCP in theory may be a separate body from an exchange (e.g., LCH, formerly called London Clearing House, in relation to London International Financial Futures Exchange [LIFFE]) or may be in-house (e.g., the clearing arm of Singapore Exchange [SGX] or Hong Kong Exchange being part of the exchange group).

However, in the 21st century, the European Union (EU) decided to open up the market for more competition in terms of trading venue or clearing services in the Markets in Financial Instruments Directive. ${ }^{8}$ The EU has abandoned the traditional vertically organized silo approach so that trades conducted in an exchange can now be cleared in different CCPs (Financial Times 2008). This development in Europe will offer another layer of interactions (between exchanges and CCPs) and more interactions for cross-border trading and clearing in the future for Asian traders.

There is no clear prospect of Asian markets adopting the EU model at the time of writing. Countries in the Asia Pacific region are not as integrated as the EU, even considering the ASEAN Economic Community in Southeast Asia. With the market and regulatory framework fragmented by national borders, it is understandable that national regulators would prefer the vertical silo model, which is also easier for the regulator to control. It remains to be seen whether any major Asian market is willing to break up the vertical silo model to accommodate more competition of trading and clearing services. This also means that the path of development of the futures scheme as a whole might diverge to a certain degree in the future between the East and West depending on the development of the market and regulatory environment.

\section{Signs of Mimetic Isomorphism in the OTC Market}

The OTC market has developed a monopolistic governance regime in the ISDA master agreement to the point that it is virtually the only TBG scheme for the OTC derivatives market, at least before the global financial crisis (Porter 2014). The OTC market also shows emerging signs of polycentrism as national regulators have sought to regulate it since the global financial crisis. One observer estimates that approximately $90 \%$ of the USD $\$ 600$ trillion aggregate notional amount of OTC derivatives are processed under one or another of the ISDA forms (Henderson 2010a; Rauterberg and Verstein 2013). Given the size of the global OTC derivatives market, it is notable that the market has developed such a singular and dominant documentation system. The rise of the ISDA master agreement system as the dominant contract form governing the OTC derivatives markets could be seen as a result of normative isomorphism.

ISDA's initial goal was to create standard documentation so as to facilitate trading. As one observer noted, the "ISDA's limited early role was to standardize documentation, a role which quickly expanded into lobbying to create greater legal certainty in derivatives" (Henderson 2010, 20). As OTC derivatives grew exponentially in 1980s, the market needed a standard set of documentation to provide a contractual platform for trading (Porter 2014). ISDA, as the association of international banks and dealers operating in the OTC derivatives market, filled the gap.

On this basis, international banks were the main drivers and vehicle to spread the usa of the ISDA standard form to other areas of the world, indicating a sign of normative isomorphism. On the one hand, a trader in smaller markets most likely had to trade with major global dealers, who were accustomed to the ISDA form and would probably prefer to use it to reduce compliance costs. On the other, even without trading with major global dealers, derivatives traders outside the US, UK and Europe still benefit from adopting the ISDA form because it is always easier to apply a form that has been created and tried out in established markets, similar to the adoption of the futures exchange governance model discussed above. Even without transacting with a Western bank as a counterparty, using a form that has been tried in larger markets is a safer choice than writing a new contract from scratch. Moreover, if an Asian bank enters into 
back-to-back transactions with a foreign bank to hedge a domestic derivative transaction, there should be less legal risk if all contracts are governed by the same set of contractual norms.

It is not that no one tried to offer a different version of documentation. China had its own version of standard documentation developed by the National Association of Financial Market Institutional Investors (NAFMII) (Ong and Hsiao 2013). However, this initiative was not a real competitor to ISDA. On the one hand, although the NAFMII form claims to be "presented in a more succinct manner to accommodate the unique situation of the Chinese market," the it incorporates key ideas of the ISDA standard form, including single-contract approach and close-out netting (Ong and Hsiao 2013, 78). Thus, the NAFMII form was like a copy of the ISDA form in a different language. On the other hand, as we explain below, the most critical factor perhaps is that China is not the epicenter of global derivatives trades, with trading volume falling far behind other Asian financial centers. With Chinese traders playing a minor role in global OTC derivatives trading, it is not a surprise that the NAFMII did not have an impact in the end. Conversely, the ISDA scheme prevailed largely because the ISDA form was widely adopted by major market dealers.

In sum, in the OTC market, we have seen the rise of the ISDA standard documentation as the predominant governing norm. Similar to the futures scheme, normative isomorphism through major market dealers is the driving force behind the adoption of the ISDA scheme in the Asian market. Combined with the fact that the derivatives market grew at a lightning speed, the use of ISDA form soon achieved a scale that is hard to reverse.

It is worth noting that the adoption of the ISDA scheme in Asia followed a different path than that of the futures scheme. Asian futures exchanges are typically established under existing legal and regulatory frameworks and are often national monopolies). Thus, a country virtually copies the whole governing mechanism from the West. In contrast, the rise of ISDA scheme occurred without a specific legal mandate. The ISDA scheme prevails in the context of the dominance of Western markets and marketmakers. Asian countries played more of a reactive role when receiving the ISDA scheme.

\section{Toward Coercive Isomorphism and Divergence after the Global Financial Crisis?}

Before the global financial crisis, the futures scheme and the ISDA scheme seemed to follow two parallel lines, each governing its own domain. However, the global financial crisis changed the scene and forced more interactions between the two governing mechanisms. Between West and the Far East, we suggest that there are not only signs of coercive isomorphism but also the potential for divergence in the governance of derivatives markets.

In 2009, the $\mathrm{G} 20$ declared a commitment to strengthening the international financial regulatory system. In particular, the G20 decided that "[a]Il standardized OTC derivative contracts should be traded on exchanges or electronic trading platforms ... and cleared through central counterparties by end-2012 at the latest." 9 Moreover, "OTC derivative contracts should be reported to trade repositories"; ${ }^{10}$ otherwise they "should be subject to higher capital requirements." 11 In short, the G20 adopted three main regulatory reform proposals:

- The trading mandate: mandatory trading on an exchange;

- The clearing mandate: mandatory clearing through a central counterparty, or CCP; and

- The reporting mandate: mandatory reporting to a trade repository.

The primary goals were to control counterparty risk, improve transparency and prevent systemic risk via the derivatives market.

One result of these reforms is more interactions between the futures schemes and the ISDA scheme. With the clearing mandate, more OTC derivatives are forced to be cleared by a CCP. According to ISDA, about $82 \%$ of the total notional amount of OTC derivatives were cleared as of early April $2016 .{ }^{12}$ 
This makes major CCPs the ultimate counterparties for trillions of dollars of trades. In this way, many OTC trades are governed partly by the ISDA scheme (before clearing) and partly by the futures scheme (after entering into the clearing system). To compete for a bigger share in the global clearing market, some Asian markets started to clear OTC trades even before the implementation of the clearing mandate. For example, the SGX started to clear OTC derivatives as early as 2010, and the Hong Kong Exchange launched its OTC clearing services in 2013, before implementing the clearing mandate. To facilitate the migration, the ISDA has actively offered solutions by offering standard documents to complement existing ISDA master agreements (e.g. the ISDA/FIA Cleared Derivatives Execution Agreement or ISDA/FIA Client Cleared OTC Derivatives Addendum).

However, if we take a larger view, Asian countries have been relatively slow to implement the trading and clearing mandates compared with the US and Europe, though the reporting mandate has been largely implemented in at least Hong Kong and Singapore (Gao and Chen 2017; Chen 2016). What could be delaying the implementation of the clearing and trading mandates in Asia?

We suggest that the delay of implementation of the clearing mandate in Asia may reflect conflicting driving forces behind the interactions of governance schemes. The global financial crisis was clearly the single dominant event that drove the regulatory reforms. However, since it took place mainly in the West, the reforms aim at Western market infrastructure. Since it might not be that difficult to move trading activities outside the US or Europe, major Western markets push major Asian markets like Singapore and Hong Kong to accept the new regulatory norms (i.e. the three mandates) through international organizations such as the Financial Stability Board and the Bank of International Settlement.

While many Asian markets, especially financial centers such as Hong Kong and Singapore, would like to gain more market share in global derivatives trading (or even in clearing services), the ability of Asian countries to compete with Western giants through different regulatory or governance regimes is restrained by laws in the Western markets. For example, there is a clear concern in the US and EU to prevent their traders from circumventing American and European regulations. Thus, a US trader may not simply clear a trade in any CCP outside the US. In order to meet the local clearing obligation by submitting a trade to a foreign CCP (i.e. so-called 'substituted compliance'), the foreign market must have similar regulatory infrastructure to that in the US. ${ }^{13}$ The EU has a similar rule. ${ }^{14}$ As major derivatives dealers are mostly in the US or Europe, rules restraining substituted compliance have induced major Asian market regulators to adopt rules similar to those in the US or EU. Thus, Asian countries have little choice but to accept the mandates if they wish to create or maintain a prosperous derivatives market. The Singapore Exchange (SGX) was the first Asian market to be recognised by the US Commodity Futures Trading Commission, in 2013 (Grant 2013). Both Singapore and Hong Kong obtained recognition from the EU as 'equivalent' CCPs in 2014. ${ }^{15}$ Whether such uniformity is good or bad for the market is another question (Griffith 2014). Therefore, we suggest that Asian markets were, in a way, coerced to adopt the mandates to force trade reporting and centralized clearing before mandatory exchange trading of derivatives, showing signs of coercive isomorphism that we did not see before the global financial crisis.

However, in the case of centralized clearing, there are obvious national concerns that would affect the strategies adopted by Asian markets to implement the mandates, which could produce a certain degree of divergence. For example, Asian markets still need to maintain financial stability and the solvency of their own clearing system. For the clearing mandate to succeed, a CCP, as the ultimate risk taker of cleared contracts, must stay solvent and have enough opposing trades to reduce risk exposure. Large CCPs in the West enjoy some competitive advantage as they are bigger, have a larger volume of trades and might have a better pool of liquid assets as collateral. Thus, Asian regulators would face a dilemma. On the one hand, an insistence on local clearing may drive traders away if their home countries do not allow substituted compliance, or may increase systemic risk if liquidity is limited. If they allow substituted compliance, Asian regulators may face a strong extraterritorial effect of US or European regulations and the risk of negative externalities because they do not have the power to regulate US or European CCPs, 
whose failure would have wide repercussions and spill-over effects for Asian traders who clear their local trades in the West. Those factors might explain why both Hong Kong and Singapore adopted the clearing mandate but delayed its implementation.

In contrast, such national concerns do not necessarily affect the reporting mandate, as transparency and data protection-the mandate's major concerns-do not have implications for solvency or national economic policy. Even if a trade is reported to a trade repository in a foreign territory through substituted compliance, a local regulator might still acquire trading information though regulatory cooperation. As mandatory trade reporting generally improves market transparency, Asian regulators have less concerns in implementing the reporting mandate for local market participants.

The trading mandate provides the strongest form of forced interactions. By forcing trades to be conducted in an organised exchange, it compulsorily attempts to shift trades from more flexible OTC markets to more organised exchange markets. If implementing the clearing mandate is already difficult, it is obvious why Asian regulators are not very keen to implement the trading mandate. After all, the rule favours large Western exchange operators over Asian exchange operators, who are still more nationally based and less consolidated than those in the US or Europe).

However, one point worth noting is that the reforms of the OTC derivatives markets have led to a proliferation of trading platforms outside existing gigantic exchange operators like CME and Eurex. Those platforms flourish not as a formal large exchange operator but as a 'swap execution facility'16 in the US or an 'organized trading facility' in Europe. ${ }^{17}$ Those are platforms that offer trading information (e.g. price) and mechanism to execute trades for parties. They are not futures exchanges but are in a smaller scale. It is also uncertain whether those trading platforms are running on a common governance model like a futures exchange. The co-existence of large exchange operators and smaller trading platforms on top of CCPs may provide a further study of interactions of TBG schemes in the future.

\section{Conclusion}

The governance of the global derivatives market is polycentric, with norms generated at both national and transnational levels. There are some isomorphic forces behind the interactions of schemes governing this market. Those forces affect rulemaking processes across national borders, resulting in different degrees of interaction between different regulatory regimes and governance schemes.

There are two main areas of transnational business governance interaction between West and East in our case study: the multiple futures schemes governing the future markets, contrasted with the single and monopolistic ISDA scheme governing the OTC derivatives market. The governance structure of a futures scheme has been successfully copied into Asian markets showing signs of mimetic and normative isomorphism. In addition, the rise of the ISDA scheme is a product of economic power and it prevails even in Asian markets through professionals and major market dealers, again suggest the power of mimetic isomorphism. After the global financial crisis, new regulations forced more interactions between the two schemes by prescribing mandatory centralized clearing and exchange trading, showing not only the polycentric structure of regulation of the derivatives market but also a certain degree of coercive isomorphism. However, we have seen Asian countries delay implementation of those two mandates. In this case, the economic power behind the transnational flow of norms is complicated by national interests and other local economic concerns. Those are areas worth looking into in the future for further interactions between futures exchanges and the OTC market.

\footnotetext{
${ }^{1}$ The futures markets trade not only futures (i.e. standardized forward contracts) but also options and other standardized products. For simplicity, we use the term 'futures' to identify the exchange-traded market.
} 
2 Dodd-Frank Act Wall Street Reform and Consumer Protection Act, Pub.L. 111-203, H.R. 4173.

${ }^{3}$ Sarbanes-Oxley Act of 2002, Pub.L. 107-204.

${ }^{4}$ See Bank of International Settlement website: http://stats.bis.org/statx/srs/table/d5.1.

${ }^{5}$ See Bank of International Settlement website: http://stats.bis.org/statx/srs/table/d1.

${ }^{6}$ See Singapore Exchange website (Members \& Professionals): https://www.sgx.com; and Hong Kong Exchange website: http://www.hkex.com.hk/Services/Rules-and-Forms-and-Fees/Forms/ListedDerivatives/Clearing/Participantship-Membership?sc lang=en.

${ }^{7}$ See the Margin Schedule in Singapore Exchange's website: https://www.sgx.com; and Hong Kong Exchange's description of Hang Seng Index Futures: http://www.hkex.com.hk/Products/Listed-Derivatives/Equity-Index/HangSeng-Index-(HSI)/Hang-Seng-Index-Futures?sc lang=en\#\&product=HSI.

${ }^{8}$ Directive 2004/39/EC.

${ }^{9} \mathrm{G} 20$, Leaders' Statement - The Pittsburgh Summit, at 11, https://g20.org/wpcontent/uploads/2014/12/Pittsburgh Declaration 0.pdf.

${ }_{10} / d$.

$11 / d$.

${ }^{12}$ See ISDA Swapinfo website: http://www.swapsinfo.org/.

${ }^{13}$ See 17 CFR 50.52(b)(4) (2013).

${ }^{14}$ European Market Infrastructure Regulation recitals 7 and 8.

${ }^{15}$ See EU website: http://ec.europa.eu/finance/financial-markets/derivatives/index en.htm\#maincontentSec4.

${ }^{16} 1$ USC $1 \mathrm{a}(50)$.

${ }^{17}$ Markets in Financial Instruments Regulation art 2(1)(15). 


\section{References}

Bank of International Settlement. 2013. "Triennial Central Bank Survey: Interest Rate Derivatives Market Turnover in 2013."

- - . 2016. "Exchange-Traded Derivatives Statistics."

Beckert, Jens. 2010. "Institutional Isomorphism Revisited: Convergence and Divergence in Institutional Change." Sociological Theory 28 (2): 150-66.

Chen, Christopher. 2016. "Over-the-Counter Derivatives Regulation in Hong Kong and Singapore." Brill Perspective on International Banking and Securities Law 1 (4): 1-50.

Coffee, John C. 2014. "Extraterritorial Financial Regulation: Why E.T. Can't Come Home." Cornell L. Rev. 99: 1259-1302.

DiMaggio, Paul J., and Walter W. Powell. 1983. "The Iron Cage Revisited: Institutional Isomorphism and Collective Rationality inOrganizational Fields." American Sociologicla Review 48 (2): 147-60.

Financial Times. 2008. "Clearing the Way."

Friedman, Lawrence M. 1996. "Borders: On the Emerging Sociology of Transnational Law." Stanford Journal of International Law 32: 65-90.

Gao, Simin, and Christopher Chen. 2017. "Financial Transnationalism and Financial Regulation Change: A Case Study for Derivatives Markets." European Business Organistion Law Review 18: 193. doi:10.1007/s40804-017-0064-4.

Grant, Jeremy. 2013. "SGX Approved for US Derivatives Clearing." Financial Times.

Griffith, Sean J. 2014. "Substituted Compliance and Systemic Risk: How to Make a Global Market in Derivative Regulation." Minnesota Law Review 98: 1291-1373.

Henderson, Schuyler K. 2010a. Henderson on Derivatives. 2nd Ed. LexisNexis.

Henderson, Schuyler K. 2010b. Henderson on Derivatives. 2nd Ed. London: LexisNexis.

Kanda, Hideki, and Curtis J Milhaupt. 2003. "Re-Examining Legal Transplants: The Director's Fiduciary Duty in Japanese Corporate Law." American Journal of Comparative Law 51. 2003: 887-901.

Koh, Harold Hongju. 2006. "Why Transnational Law Matters." Penn State International Law Review 24: 745-53.

Kokkoris, loannis, and Rodrigo Olivares-Caminal. 2007. "Some Issues on Cross-Border Stock Exchange Mergers." U Pa J Int'I L 29. 2007: 455-526.

- - . 2008. "Lessons from the Recent Stock Exchange Merger." J Competition L \& Econ 4. 2008: 83769.

Leicht, Kevin T., and J. Craig Jenkins. 1998. "Political Resources and Direct State Intervention: The Adoption of Public Venture CapitalPrograms in the American States, 1974-1990." Social Forces 76 (4): 1323-45.

Ong, Kingsley T.W., and Mark W.H. Hsiao. 2013. "From ISDA to NAFMII: Insolvency Stalemate and PRC Bankruptcy Jurisprudence." Capital Market Law Journal 8 (1): 77-88.

Porter, Tony. 2014. "Technical Systems and the Architecture of Transnational Business Governance Interactions." Regulation and Governance 8 (1): 110-25. doi:10.1111/rego.12016.

Schammo, Pierre. 2008. "Regulating Transatlantic Stock Exchanges." ICLQ 57 (4): 827-62.

Shaffer, Gregory. 2012. "Transnational Legal Process and State Change." Law \& Social Inquiry 37: 22964.

Teubner, Gunther. 2004. "Global Private Regimes: Neo-Spontaneous Law and Dual Constitution of Autonomous Sectors?" In Public Governance in The Age of Globalization, edited by Karl-Heinz Ladeur, 71-87. Ashgate.

Trampusch, Christine. 2000. "Grenzen Der Diffusion. Die Formative Phase Der Arbeitsmarktpolitik in Den Niederlanden." In Sozialmodell Europa. Konturen Eines Phanomens, Jahrbuch Fur Europa Und Nordamerik, 153-77. 
Walter, Andrew. 2008. Governing Finance: East Asia's Adoption Of International Standards. Ithaca: Cornell University Press.

Weber, Rolf H. 2010. "Multilayered Governance in International Financial Regulation and Supervision." Journal of International Economic Law 13: 683-704.

Wendt, Froukelien. 2015. "Central Counterparties: Addressing Their Too Important to Fail Nature." WP/15/21. 